\title{
Interpretive Use: Translating Intensification
}

\author{
Vicente López Folgado \\ University of Córdoba
}

ff1lofov@uco.es

\begin{abstract}
My aim here is to discuss first the fitness of a cognitive theory like RT when approaching the interpretive operations taking place in the translating activity. The basic notion of interpretive resemblance is put forward instead of the traditional one of equivalence. Secondly, the application of this cognitive framework is here discussed so as to tackle the case of intensifiers as a vague, "connotative" field of interpretation that puts to test the inferential work of translators. I then focus on a few varied examples of actual translations which illustrate some of the contextual effects conveyed by intensifiers of various kinds.
\end{abstract}

\section{Introduction}

We will assume at the outset that translation is a human activity which involves a linguistic act, namely the rendition into a target language (TL) of a text (a collection of interrelated utterances) that had already been produced in a source language (SL). A fruitful, relevant way of approaching such rendition is by accounting for what goes on in that linguistic act in terms of communication process. This means that alongside the linguistic knowledge, a host of other neighbouring fields of knowledge are involved in it such as the complex phenomena traditionally described by theoretical humanistic sciences like sociology, psychology, ethnography, and the like.

Most modern linguistic approaches make avail of a structural type of methodology which basically entails implementing some version or other of a fixed-code semantic model that, as pointed out by Gutt (1991), has allegedly proved inadequate to describe what goes 
on in linguistic communication and more specifically in that special human operation called translation.

However, if we approach translation as a cognitive activity, there is little need for describing in much detail the manifold connections translation has with other possible related fields of study. The emphasis should instead be laid on a double aspect of the phenomenon of translation. Firstly, on the translator's ability to process all the information stemming not only from the meanings conveyed by the linguistic code of the source text (ST), but also and crucially, from the relevant contextual effects produced by her active inferential work during her actual reading of the literary text involved (Pilkington, 1991). Secondly, on the reader's ability to get access both to the information provided by the linguistic code of the text concerned and to further relevant information derived from the translator's interpretation of it. This last operation is done through inferential work aimed at yielding enough contextual effects the reader deems worth while pursuing, as often claimed by Sperber and Wilson's (1986) seminal work.

This last aspect of additional contextual effects should be considered of the utmost importance when translating aspects of texts whereupon we attempt to focus in the present paper.

Suppose a translator comes across this sentence:

(1) a. Jill is pretty wrong there.

b. Jill esta en eso pero que muy equivocada.

Some would suggest that there is an obvious lack of literal equivalence relation between the two utterances. It seems to me though that the Spanish expression marks a higher degree of intensification than the English. The expression "pero que muy" seems to me that it suggests a degree of intensification and emphasis that "pretty" lacks (a good rendering of it in English would be "very, very" or "most" i.e. the highest degree of intensification). The translation is then a bad one, no matter the intonational emphasis (focus stress) the English sentence may have been uttered with.

On the other hand, there would be no way of knowing if the utterance (1b) translates (1a) appropriately, if the translation had been a more ambiguous expression like "un tanto" or simply "bastante", unless we look into the contextual effects produced by the use of the intensifiers in the reader's representation of both utterances; in the last case the truth conditions of the proposition need an enrichment so as to disambiguate the vague meaning coded by the intensifier. In sum, it is a major translator's job to account for all the information accessed in the act of reading the SL utterance and then do the same in the act of rendering that sentence into the TL. Now the thorny problem the reader-cum-translator has to face is, how will she assess all those nuances of meaning, the so called 'connotative meaning', that are supposed to be reached through implicative mental operations? We assume that a case in point is provided by intensifiers as they are translated from one language into any other. 
All we know is that this last cognitive operation is reached through inferential work which is the way our whole mental activity works. As argued by Sperber and Wilson:

Propositional contents and attitudes thus seem to provide the only relatively solid ground on which to base a partly or wholly inferential approach to communication. Too bad if much of what is communicated does not fit the propositional mould (Sperber and Wilson, 1986: 57).

In fact we may perhaps put forward the hypothesis that (1a) seems to bear a certain tone of modal mitigation here. There seem to be a hedging phenomenon which suggests a polite form that disguises a total disagreement, thus bearing at least some resemblance to the less polite unmitigated Spanish utterance. Now the question which immediately arises is, on what grounds can we safely entertain that hypothesis? Could it not be a far-fetched assumption? The answer to this crucial question lies, to a great extent, in our belief in our own representations which are crucially based on our own knowledge of the two languages at issue. Representations (Sperber and Wilson, 1986) are hypotheses (strong or weak assumptions such as beliefs, intuitions and desires) about the world we entertain in our minds. A grammatical functional model of communication would insist on the scalar degree of modality in the English code: from epistemic and deontic modality to attitudinal adjectives and intensifying adverbs. By contrast, a cognitive model of communication should actually lay the emphasis not so much on the semantic content, which is automatically recovered by our language module but on the hearer's recovery of the final interpretation that the utterance has. .

As able speakers then of at least two languages, translators should then be competent interpreters in both languages and for the same token they should be able in principle to be aware of the frequently subtle differences between the two linguistic codes.

\section{Interpretive use}

The case of translation is that of an interpretive use of language (Gutt, 1991). It is the reader-cum-translator's competence what is at stake here since she's the sole referee. In effect, it is in her mind in the first instance where the whole double process of interpretation and production takes place. She therefore must be the most relevant judge when it comes to deciding what subtle or big differences there are between two sentences in two languages, if there is any.

If a sound linguistic knowledge of the two languages involved seems fundamental for the interpretation of utterances, so does the knowledge (various representations like beliefs and assumptions) of the world. But then, one is tempted to ask, what role does the so often invoked semantics of a language play in the whole affair of communication? (Coseriu, 1977). As a conventional, objective description of the meanings of linguistic expressions (mostly single words), its job seems to be that of providing an undetermined blueprint for propositions. Then it is the task of pragmatics to show how the hearer/reader is able to 
develop such blueprint into a complete proposition with the crucial help of her computing of contextual knowledge. (Blakemore, 1992: 43).

It is my purpose in this paper to examine some of the effects produced by certain words and expressions that are conventionally, if somewhat misleadingly, called "intensifiers" (for lack of a better word). A further apparently synonymous term, "degree adverbs", are types of words which, closely examined, are not so easy to pin down as semantic bearers of some fixed, accurate meaning. They therefore pose many problems for the translator who has often been misled by traditional semantic theories which attempt to approach the whole process of translation in terms of "equivalence" in the target language. The translator guided by such principle would be so concerned with context independent words that she will surely be bound to do mistaken operations such as the following: a) leave out her own response to the information provided by the work concerned; b) turn a blind eye to her faith in ber own abilities as language speaker; and c) pay little attention to the modification of her own cognitive environment.

Furthermore, the effects of the translator's reading could and should be compared to the one produced in a reader of the translation of that text (Dahlgren, 1998). Since the typicaily descriptive concept of linguistic equivalence seems to fail to be an adequate notion when one cares to report about the mental operations carried out in translation, we simply will do without such a misleading concept. Instead we will be concerned with resemblance as the dynamic notion that would best account for the possible contextual effects produced by such linguistic units in the actual utterances of texts.

Gutt (1991: 33) provides a good example of an intensifier in relation to non literal language promoting economical communication:

(2) a. Bill is a real ganster.

b. Bill es un auténtico ganster.

Here both the English and the Spanish proposition are likely to be read metaphorically as dealing with someone ruthless in his practices or someone whose behaviour is threatening. Let me add that some of the effects of that implicature are caused no doubt by the effect produced in our minds of the English intensifier "real", which has been rendered in Spanish by means of "auténtico". They seem to cause resembling effects in the reader.

So the intended interpretation shares with the utterance a number of assumptions which are implicated precisely in this particular context. The first propositions (2a) then is said to bear some implications which account for the resemblance of the representations of the second proposition (2b) in the utterances of the two languages. The Spanish and the English version of the proposition should then trigger "similar" representations. It is on these grounds in fact that we are allowed to conventionally state that the utterance in language $B$ (the so called Target Language) can be more or less faithful to the utterance in Language A (the so called Source language). If English "real" would have been translated in that utterance by Spanish "real" (as it is possible in other cases) then presumably the set of assumptions raised in the reader would have differed considerably. 
According to Blakemore (1987) resemblance in content of two given utterances can be close or distant depending on the variable shared contextual implications they give rise to. We may then say that representation by "resemblance" with respect to degree words crucially involves some implicatures that promote the speaker's attitude denoting quantity uncertainty and doubt concerning the degree of commitment to the truth of the proposition.

\section{Description vs interpretation}

Does a structural (functional or not) theory fare well when they come to grips with the transcodification problem? Let me remind the reader that a structural (functional) theory is based on a paradigmatic view that attempts to predict a network of meaning relations as resourceful linguistic choices whereby a speaker can pick a linguistic form or feature out of a large number of available choices in a given system. Thus as speakers of English we have a grammar as a code readily available, even if most variable according to general social factors. Such grammar is made up of inter-related systems which are to be chosen at any point in the discourse process. It is therefore on the speaker's onus to use one or another meaning as a manifestation of her linguistic behaviour in accordance with the social context (Halliday, 1985).

But is this a convincing way of explaining what goes on in actual communication? Let's say that only to some extent, since a taxonomical (albeit functional) approach would typically focus on linguistic entities, that is, the meanings of words or expressions codified as objective resources described $a$ priori which are at the speaker's disposal in a network of choices in some (social, therefore external) context. Moreover, such descriptive network of features of contextual factors must be in a constant process of expansion since they are either too vague or too inappropriate, which means that there's plenty of guesswork ahead for the reader and translator if she wishes to get an accurate equivalent expression.

Now, seen from a cognitive perspective, Blakemore (1987) argues that some expressions (such as so and after all) do not contribute to the truth conditional meaning of the utterance, since they do not represent concepts. Degree adverbs, however, represent some concepts (minimizing, downgrading, etc), and therefore they have a clearer semantic referent. It is true, on the other hand, that they sometimes show a fuzzy, underdetermined nature, typical of many expressions in the linguistic code (Carston, 1991a;, 1991b). They need then to be accounted for in terms of the semantic information they provide, bearing also in mind the surplus information providing some contextual effects. The latter would typically give rise to slight modifications of one's cognitive environment. In sum, translation should never be approached as a case of equivalence, a hypothetical concept hard to test and falsify, but as a case of resemblance. Similarity of effects produced by two resembling utterances in the reader's representations would be a much more appropriate notion faithfully accounting for what actually goes on in bilingual communication (Gutt, 1991).

Consider these examples: 
(3) a. I can't hardly say that I know him.

b. Yo no diria que le conozco bien.

Linguistic structures can differ as means of expressions and as blueprints for inferencial interpretation. That both utterances resemble each other is a matter that goes beyond comparison of formal structures. The use of the minimiser hardly is rendered in Spanish by a negative affecting the verb and a positive adjective bien here. It seems quite evident that both utterances have similar implications.

Translating from one language into another then is a matter of interpretive resemblance in the listener/reader's representations of propositions expressed in both the utterance of language $A$ and the utterance of language B, no matter how far away or how close the languages are formally and/or typologically. For most theories of translation it seems reasonable to claim that familiar languages should be able to share formal features of the linguistic code that to some extent favour the resemblance of the propositions formally expressed in such languages. But this is hardly the point we should make in the present approach. Rather, the interesting point that should be raised in translation theory is that we should be able to explain why apparently dissimilar sentences can resemble each other in inferential terms even if their coding forms differ.

In the example (1) above the use of the intensifier "pretty" before the adjective "wrong" would have the implicature that Jill was totally wrong, but for polite reasons (a negative face issue, according to Brown and Levinson, 1987) one tends to mitigate the harsh effects of a complete negative utterance. So the downioner "pretty" resembles the "totally" but with the implicated effect of polite mitigation. In Spanish, however, the speaker chose to say squarely that Jill is wrong.

Consequently, one is tempted to think that the form of a language is a kind of centuries old resourceful deposit where much knowledge of the speakers is somehow stored. However this last statement does not justify a mere formal comparison of two structures (as many translation theorists have done and still do today) with the purpose of indicating equivalence of meaning of sentence $A$ and sentence $B$.

\section{The case of Intensifiers}

Halliday (1985: 171) formally describes intensifiers under the heading of functional submodification, even if sometimes such class of word can disturb the natural ordering of elements in the (nominal)group.

(4) a. a quite easy problem.

b. quite an easy problem.

The term intensifier suggests a particular semantic type of adjective modifier, one which very often corresponds to adverbs of degree. Verbal degree modifiers are not rare either. 
However, most of them show a double function, since they can be used both as adjective and as verbal modifiers. The class based on syntactic grounds is too varied to have a homogeneous classification. Semantic division too shows that they are not totally similar and have an uncertain area at the border (Allerton, 1987). This author, in fact, goes on to classify intensifiers into four major semantic categories: degree, aspect, manner, and method, which in turn modify both adjectives and lexical verbs. This is an overall classification which is in fact grounded on a mixture of formal and semantic criteria.

Quirk et al. (1985: 445-446, 589f.) however had typically split up adjective and verb modifiers of degree into a more detailed content categories:

"amplifiers" which scale upwards.

"downtoners" which have a lowering effect.

"emphasizers" though they bear resemblance to 'focusing disjuncts'.

Then they subdivide the first two groups into the sub-headings:

amplifiers: "maximizers" (completely) and "boosters" (very).

downtoners: "approximators" (almost), "compromisers" (more or less), "diminishers" (partly) and minimizers (hardly).

This very detailed taxonomic classification can be criticized on various counts, the most important being that like most semantic taxonomies this is as arbitrary as any alternative proposed ad hoc. In fact the meaning of quite a few of the words under those sub-headings become more concrete and determined when they appear in context. Therefore the above categories are bound to belong to one or several of the semantic groups proposed.

If the meaning of most words were settled before any receiver of the utterance added a cognitive context to it, then the code would be an invariable not actually worth interpreting, but a given which would only be decodified. Then the whole process of translation would be viewed as a descriptive operation of comparable linguistic structures (Catford, 1965), where the unchanging static value of "equivalence" would reign supreme. Furthermore, the often quoted "faithfulness" would be a quality to be displayed by objective structures of the languages involved. By contrast, communication is primarily and above all inferential, as Sperber and Wilson (1986) rightly claim.

Once a text (collection of relevantly interrelated utterances) is translated the resemblance is all the more noticeable because it shows inevitable variations owed to modifications not only of language but also of specific cultural features. As Gutt (1991: 59) suggests when discussing this point:

The writer of the German text (his example) may have found the Finnish original helpful in his task, but the text he created was intended to communicate in its own right, and to be read and understood as such. It may be worth pointing out that this distinction between descriptive and interpretive use applies not only to interlingual communication - parallel cases occur intralingually as well. 


\section{Degrees of intensity}

It would be perhaps just to say that the issue of intensifiers is a somewhat difficult and slippery matter for the translator since what is often at stake is in fact a question of "more or less" depending on contextual assumptions. But that is hardly an excuse for failing to attempt to reproduce some similar effect in the TL reader. In a trilingual version we read:

(5) a. The finish would be a sight to see

b. Das Ende wurde ein sehenswertes Schauspiel sein!

c. El final debia ser todo un espectáculo

A Gricean (1975) approach would involve an implicature that accounts for the clash between the furst maxim of quantity and the second maxim of truthfulness. The speaker would have followed the latter and then flout the former. Understatement and overstatement are to some extent noticeable changes which affect quantity. The Spanish translator seems to have decided to use the maximizer todo which is absent in the English original. This use of the intensifier actually resembles the English use of quite absent in the original in this particular case. By and large the translators have found easier to alter the degree of the information required than to alter the truthfulness of the statement.

Thus in the next examples the relative scalar criteria imposes itself when translating the words of the type quite and such. The following translation can be critizised, as demasiado is situated to one end of the quantitative semantic scale which such would hardly occupy. So perhaps tan would do the quantitative job.

(6) a. It's been such a silly game to play.

b. Era un juego demasiado estúpido.

Now there are various other expressions in the languages which are colloquially used to mean intensification. Not only are they used in adjective pre-modification with an undeniable exclamatory value, but also with some value-laden words:

(7) a. The mayor of Madrid is such a fool.

b. Anda que no es tonto el alcalde de Madrid.

Quite interestingly, Bolinger (1972) suggests that nouns like fool can also be gradable, in the sense of a scale of assessment, and of degree. Those nouns derive from gradable adjectives, as we can also see in the colloquial expressive formula used by the Spanish translator. The degree word here seems to convey the additional connotation of criticism expressed in colloquial terms.

In fact the use of such is grammatically restricted to the indefinite determiner such $a$ and can be interpreted as an exclamation, like in the present case, and not as a definite 
determiner *such the/my etc. Furthermore, there are nouns like doctor, bachelor, etc which are not to be used in that way.

The lexical meaning of the adjective is determinant in the interpretation of the degree modifiers such as absolutely, extremely, very, pretty, rather, fairly, slightly, not quite, not very. The context then varies with the words collocated with them:

(8) a. This case is slightly different from last month's.

b. Este caso es un tanto diferente al del mes pasado.

Now slightly collocates (tends to appear close to) restrictively either with comparative adjective as is the case of $(8 a)$ or with adjectives which have a negative shade of meaning. Thus, slightly unpleasant, boring, tiresome, disagreeable (but slightly pleasant?, interesting?, stimulant?, kind?).

In a Spanish version of the short story by Saki "The Open Window", we note the relative failure to appreciate the degree in the interpretation of this type of intensifiers:

(9) a. Then you know practically nothing about my aunt?

b. ¿Entonces, apenas sabe algo de mi tia?

c. ¿No sabe, entonces, nada en absoluto de mi tía?

The intensifier practically can be taken as synonymous to absolutely, totally, but here the translator in $(9 \mathrm{~b})$ clearly has mitigated the effects of the negative, thus leading the reader to infer the implicature that the character concerned knows at least something that is worth knowing about his aunt. The understatement, if we accept (9b) at all as a resembling translation, is on the Spanish side this time. We should surely derive further implicatures if we widen slightly the context of the utterance to allow in room for our knowledge of the characters involved in the dialogue. We then propose (9c) as a closer translation, where the common expression en absoluto renders the extreme intensifier practically.

In the same translation of Saki's story we find a further variation in the degree of this type of intensifier. The overall effect again is a not very common use of understatement in Spanish (may be the contrary is closer to the truth):

(10) a. Pity you weren't out; we had quite a good day.

b. Es una pena que no salieras; hemos tenido un buen día.

The relative scalar value of intensifiers makes them difficult to be rendered in a similar resembling manner. Quite often we see departures from actual resemblance in the reception of the two languages, which easily go unnoticed by the readers, as they represent but small subtle changes.

Look at this trilingual translation of Mark Twain's A Table-Talk:

(11) a. It was getting pretty sultry for me. 
(11) b. Mir wurde schwül und schwüler.

(11) c. Empezaba ya a sentir bochorno

Neither the German nor the Spanish version are formally equivalent. And they need not to be. The interpretation of the German version focuses on the increasing graduality of the mental state (schwül and schwüler), while the Spanish version stresses the time adverb ya so as to reinforce the inchoative process used. The intensifying, assessing meaning of pretty seems to be absent in either case.

The fact that the grammatical resources to implicate assessment of degree shows much linguistic variation speaks loudly in favour of the interpretive character of all translations. It would be almost impossible to describe accurately all the possibilities a producer or a translator has at her disposal to access to certain effects. But in the event that this could be achieved, there would still be the problem of attaching a meaning to a form in an accurate way.

Notice, for instance, how the translator of a story has reached some similarity of effect (or not quite) by means of a formally different expression:

(12) a. I'm just simply crazy about that man.

b. La verdad, ese hombre me vuelve loca.

Here the evaluative intensifiers $j u s t$ plus the understating degree adverb simply before the noun crazy, is rendered by a disjunct phrase (Quirk, 1985) which is also evaluative and have some implicatures of the type I must admit, there's nothing I can do about it. All we can say here is that the translator somehow managed to put across similar relevant information in this case. And this has been done only by linguistic means. In fact the basic claim of relevance theory is that in processing information the hearer focuses her attention on the achieving the greatest possible cognitive effects while doing the smallest possible amount of processing effort.

Sperber and Wilson (1986) postulate that human communication is driven by relevance and the maximization of relevance. By this notion they mean that information is relevant to somebody if it yields enough contextual effects worth paying attention to. They are of three types: strengthening previous assumptions, contradicting them, and generating new assumptions or implicatures.

Look at the following example from an early Spanish translation of Stephen Crane's famous work The Red Badge of Courage:

(13) a. 'Yank', the other had informed him 'yer a right dum good feller'.

b. Yanqui -le había dicho el otro- eres un muchacho requetebueno.

The spelling here reflects the native dialect where the intensifying cues are not just the common modifier right but also the modifying noun dum (damn) with respect to the adjective good. Now the Spanish version yields sufficient contextual effects through that 
colloquially expressed amplifier (a real booster) with some affective, positive overtones. What seems important then is the similarity of the effects yielded by linguistic means, which actually change our cognitive environment and can be variously achieved.

By contrast, we can come across the extreme case where no intensifier is translated and still achieve the intensity through lexical means. In a good recent Spanish translation of Gulliver's Travels we read this line:

(14) a. I was extremely tired.

b. Estaba exhausto.

This suggests that we need not follow too closely a formal or functional grammar which describes classes of words neatly set in contrast with the correspondent same type of words in other languages. We often find a zero realization of a specific class of words.

Now we will never harp too much on the idea that utterances are far richer in effects than a mere formal description of sentence meaning would allow us to entertain. To illustrate this further I would like to draw the reader's attention to three different instances.

First note the intensification effect that a certain type of adjectives can cause in the reader of English and their actual renditions into other languages:

(15) a. It was open - wide, wide open- and I grew furious as I gazed upon it.

b. Es war offen - weit, weit offen- and ich wurde rasend, als ich darauf starte.

c. Lo tenia abierto - muy, muy abierto-y me enfurecí más al contemplarlo.

While the German version of The Tell-Tale Heart by E.A. Poe makes a servile use of the same grammatical structure, where the effect of the repetitive descriptive adjective is that of iconic intensification, the Spanish translator fully reflects this same effect by using a native language structure in his version. $\mathrm{He}$ is to search, however, for alternative translations that sound more familiar to Spanish readers. There are often expressions where to choose from that sound like more typical Spanish intensifiers:

(15) d. Lo tenía abierto de par en par y me enfurecí más al contemplarlo.

Secondly, a further example of lexicalization of the degree of intensity is the formulaic comparisons. This is a very rich and productive field of study in some languages, like Spanish. One example of this type of amplifying effect can be the one we find in the well known American novel The Catcher in the Rye:

(16) a. They are nice and all - I am not saying that-but they are touchy as hell.

b. Son buena gente, no digo que no, pero a quisquillosos no hay quien les gane.

Thirdly and lastly, there is a further related phenomenon, called hedging which I will briefly comment upon. By using "hedges" the writer makes manifest her intention of being not too 
assertive and of sounding tentative. Linguistic hedges are, according to Lakoff (1987:462), "words or phrases whose job is to make things more or less fuzzy". I assume that there is implicit a sort of strategy in the use of these expressions aimed at avoiding facing communication directly. There is little doubt that degree words of the downtoning type (compromisers, diminishers and minimizers) are also involved here. They should therefore contribute to the truth conditions of the proposition, in spite of the inherent tentative semantic meaning they have.

To offer just one last conspicuous example of this type of reverse intensification from I will quote again the same American novel, which is characteristically plagued with expressions of that kind:

(17) a. But she wasn't exactly the type that drove you mad with desire.

b. Vamos, no era precisamente el tipo de chica como para volverie a uno loco.

The negative predication with the adverb exactly is an ironical understatement which yields the implicature of avoiding the Gricean maxim of truthfulness for being ironical and perhaps the maxim of manner for being slightly ambiguous. However, we may argue that this expressive circumlocution and the implicative constraint of the negative provides an enriching contextual effect to the information supplied by the coded proposition.

\section{Concluding Remarks}

One major point made by relevance theory is that the grammatical and lexical codes of a language are not enough to explain communication. The traditional approaches to translation have invariably focused on the more or less detailed description of that code syntax plus lexical semantics mainly. However, as I have stated above, translation is a case of practical language activity that involves both interpreting utterances information and reproducing them again. Now in order to do that, inferential work is essential in order to compute all the information intended by the writer, no matter how vague, how tentative or how "connotative" it is. Thus the overall principle of relevance cognitively guides the translator so that she may derive all the possible enriching effects the text displays.

The rendition then of the text into another language (TL) should be guided by such universal cognitive principle and thus allow the translator to give the closest resembling utterances to the source text as possible. The search for the alleged ideal equivalence between the two texts is ruled out from this perspective.

Being then led by the overriding principle of relevance means that the translator cannot rely solely on her supposedly competence of the grammars of two languages. I think that I have shown in this paper that there is in fact scarce prediction and little coincidence in the rendering of intensification. This in turn reflects the varied semantic resources in the grammatical and lexical expressions in many languages, no matter how typologically or 
historically close they are. The enrichment of assumptions in the reader can actually be reached through various other expressions than the commonly known.

\section{Works Cited}

Allerton, D.J. (1978): "English intensifiers and their ideosyncracies". In R. Steele and T, Threadgold, eds., Language Topics. Vol II. Amsterdam: John Benjamins.

Blakemore, D. (1992): Understanding Utterances. Oxford: Blackwell.

Bolinger, D.L. (1972): Degree Words. The Hague: Mouton.

Brown, P. and S. Levinson (1987): Politeness: Some Universals in Language Usage. Cambridge: Cambridge University Press.

Carston, R. (1992): "Quantity maxims and generalized implicature". UCL Working papers in Linguistics 2: 1-31.

. (1991): "Implicature, explicature and truth-theoretic semantics". In Steven Davis, ed., Pragmatics. A Reader. New York and Oxford: Oxford U. Press, 33-51

Catford, J.C. (1965): A Linguistic Theory of Translation. London: Oxford University Press.

Coseriu, E. (1977): El Hombre y su lenguaje. Madrid: Gredos (Reedic., , 1985)

Dahlgren, M. (1998): "Relevance and the translation of poetry". Revista Alicantina de Estudios Ingleses 11: 23-32.

Grice, H.P. (1975): "Logic and conversation". In P. Cole and J. Morgan, eds,: Syntax and Semantics 3: Speech acts. New York: Academic Press, 41-58.

Gutt, E-A. (1991): Translation and Relevance: Cognition and Context. Oxford: Blackwell.

Halliday, M.A.K. (1985) An Introduction to Functional Grammar. London: Arnold.

Lakoff, G. (1987): "Hedges: a study in meaning criteria and the logic of fuzzy concepts". Papers of the Chicago Linguistic Society 8: 183-228.

Pilkington, A. (1991): "Poetic effects: a relevance theory perspective". In R. Sell, ed., Literary Pragmatics. London: Routledge, 44-61.

Quirk, R. et al. (1985) A Comprehensive Grammar of the English Language. London: Oxford.

Wilson, D. and D. Sperber (1986) Relevance: Communication and Cognition. Oxford: Blackwell. 